DOI: 10.33727/JRISS.2019.2.2:15-22

\title{
Design an analysis of a straight bevel gears transmission
}

\author{
M Bucur ${ }^{1}$, S Cananau $^{1}$ \\ ${ }^{1}$ Machine Elements and Tribology Department, Faculty of Mechanical and Mechatronics, \\ University POLITEHNICA of Bucharest, Romania
}

E-mail: sorin.canaau@upb.ro

\begin{abstract}
One of the most important application in mechanical transmissions with gears is the transmission by bevel gears. In this paper we are going to perform a computerized design of the bevel straight gears transmission and the static analysis of the bevel gers transmission under load. We presume that these gears are manufactured in conical blanks by cutting, using same known methods. The static analysis is performed using the Finite Element Method. We present the results of the comportment of the system under load for displacements and stress in the region of the root of the teeth, the total displacement due to elastic deformation of the structure and the results in conditions of Hertzian contact under load.
\end{abstract}

Keywords: computerized design, mechanical transmissions, bevel gears

\section{Introduction}

One of the most important application in mechanical transmissions with gears is the transmission by bevel gear. Their purpose is to transmit power and movement by rotation between intersecting axes. An usual application is the straight bevel gears transmission where the axes are arranged at angle of $90^{\circ}$ which is the case studied also in this paper. In the scientific field of computerized design and research of bevel gears are a lot of papers of interest. Between these an important part is dedicated to the study of straight bevel gears with localized bearing contact. We mention here important papers of Litvin at al., [1],[2], [3]. But there also a lot of scientific papers concerning the comportment of the bevel gear set under load [4]

In this paper we are going to study the computerized design and the function of straight bevel gears. We presume that these gears are manufactured in conical blanks by cutting. One of the most used method of manufacture these gears from blank cones is Gleason Coniflex Method ${ }^{\circledR}$ [5]. Other well known method is Gleason Revacycle Method ${ }^{\circledR}$.

\section{The model of the bevel gears transmission}

In this chapitre we will present the design of the each gear in the mechanical transmission, the functioning set of the gears transmission and the model prepared for the analysis with Finite Elements Method. 


\subsection{Designing the geometry}

The geometry of the bevel straight gear is based on the classical geometry reference involute profile. The base design for straight bevel gears set model is presented in the figure 1. [6]

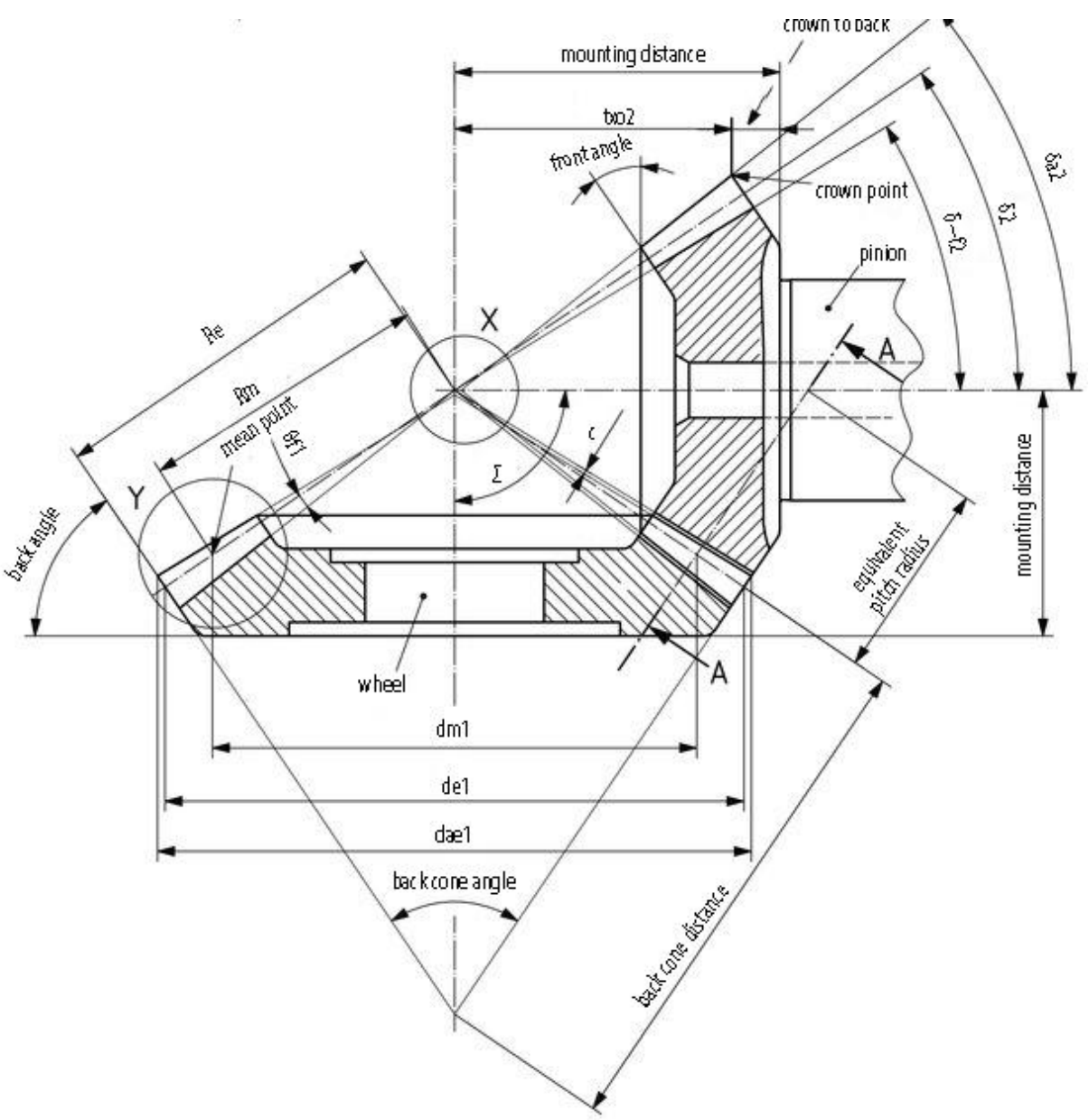

Figure 1. Geometrical characteristics of the set of the bevel straight gears - $\quad$ adapted ISO 23509:2016(en)

[6] https://www.iso.org/obp/ui/\#iso:std:iso:23509:ed-1:v1:en

but also, on the geometrical characteristics of the tool for manufacturing. In this paper, we choose to simulate the driving and driven bevel gear manufacture following the process of Gleason Coniflex method and tools.

The algorithm of the numerical manufacturing process includes the profile (which is designed with two profile curves and a curve of fillet with a radius in accordance with the fillet of the cutting tool) as we can see in figure 2(a). In figure 2(b) is represented the simulation of the $3 \mathrm{D}$ cutting process according Gleason Coniflex method. According Gleason Coniflex method are used two cutting discs or two cutting blades, each of them cutting a half of the tooth with profile. The Gleason Coniflex method is based on the application of dual interlocking circular cutters (DICC).

The elements of the geometry of the set are described in Table 1. 
This method is a hobbing method. There are two circular intermeshing milling cutters to reproduce, as a counterpart of the rack, the generating surfaces. Each profile of each side of the tooth is generated along the conical blank of the bevel gear. In figure 2(b) is represented the left part of a body of a tooth, realized by cutting with a disc with a radius fillet. In figure 3(a), 3(b) is represented the result of the numerical cutting process (simulation) of pinion - driving gear, and the wheel - driven gear. In this algorithm was tested also the geometrical fitting of the gears in the functioning conditions with null load, only in the rotation (figure 4)

In Table 1 is presented the geometrical characteristics according the nomenclature of the [7], Bevel and hypoid gear geometry, ISO 23509:2006(en), revised 2016.

Table 1. Bevel geometry characteristics for the set model.

\begin{tabular}{|lcccc|}
\hline Element & Symbol & U.M & Pinion gear & Wheel gear \\
\cline { 2 - 5 } Module (ext) & $m_{e}$ & $\mathrm{~mm}$ & 3 & 3 \\
Number of teeth & $z$ & - & 19 & 47 \\
Pressure angle & $\alpha$ & $\mathrm{deg}$ & 20 & 20 \\
Transmission ratio & $i$ & - & & $\mathrm{z}_{2} / \mathrm{z}_{1}=2.474$ \\
Outer pitch diameter & $d_{e}$ & $\mathrm{~mm}$ & 57 & 141 \\
Base diameter & $d_{b e}$ & $\mathrm{~mm}$ & 53.5625 & 12.4970 \\
Outside diameter & $d_{a e}$ & $\mathrm{~mm}$ & 63.1800 & 146.8200 \\
Root diameter & $d_{f e}$ & $\mathrm{~mm}$ & 50.8200 & 131.5800 \\
Circular pitch & $p_{e}$ & $\mathrm{~mm}$ & 8.85639 & 8.85639 \\
Contact ratio & $\epsilon$ & - & 1.31652 & \\
Whole depth & $h_{m}$ & $\mathrm{~mm}$ & & \\
Working depth & $h_{m w}$ & $\mathrm{~mm}$ & & \\
Addendum & $h_{a m}$ & $\mathrm{~mm}$ & & \\
Dedendum & $h_{t m}$ & $\mathrm{~mm}$ & & \\
Number of imaginary & $Z_{t v}$ & - & & \\
teeh & & & & \\
\hline
\end{tabular}




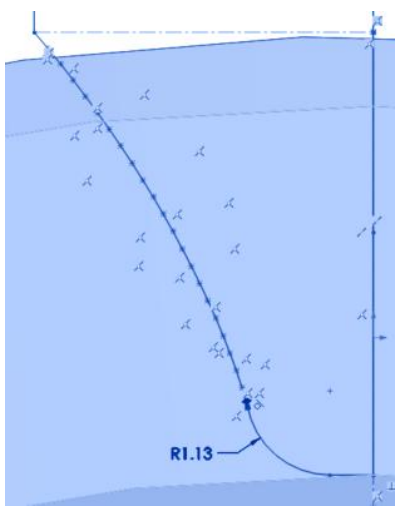

(a)

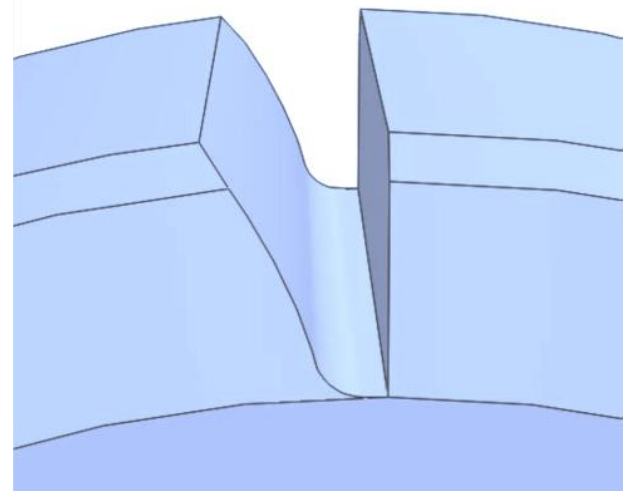

(b)

Figure 2.

(a) The involute profile fillet with the profile of the cutting tool;

(b) The simulation of the cutting process
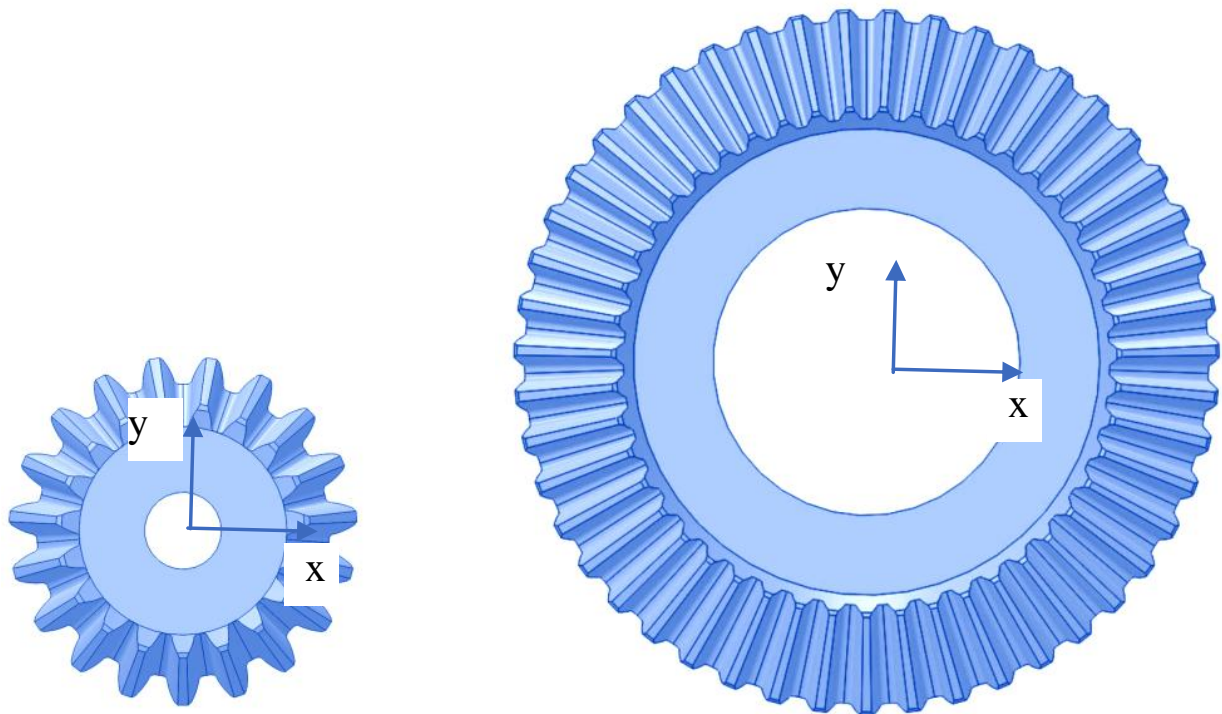

Figure 3.

(a) Pinion-driving gear; (b) Wheel -driven gear

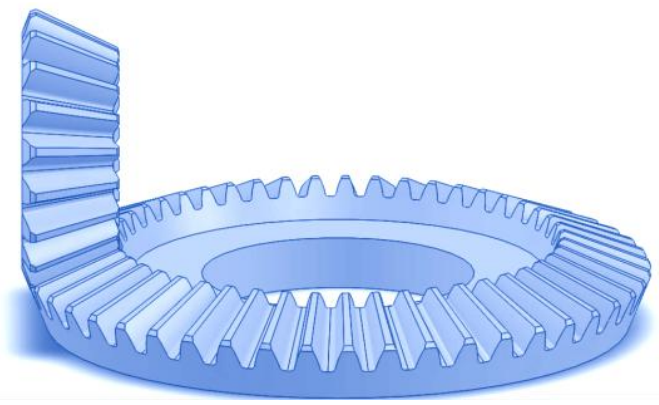

Figure 4. The gears in mesh 


\subsection{Finite Element Model}

Based on the design shown in the previous chapter a finite element model was conceived to perform the static analysis under load of a set of gears, as it is shown in figure 4 To achieve the file transfer of SolidWorks, where the solid model was created, in Ansys Workbench file, in order to perform FEM analysis, the model is saved in format ACIS (SAT). A segment of the pinion with four teeth and a segment of the gear with three teeth are used to simulate the contact in the functioning conditions. Once imported file in Ansys-Design Modeler we apply general control. The model is presented in figure 5.

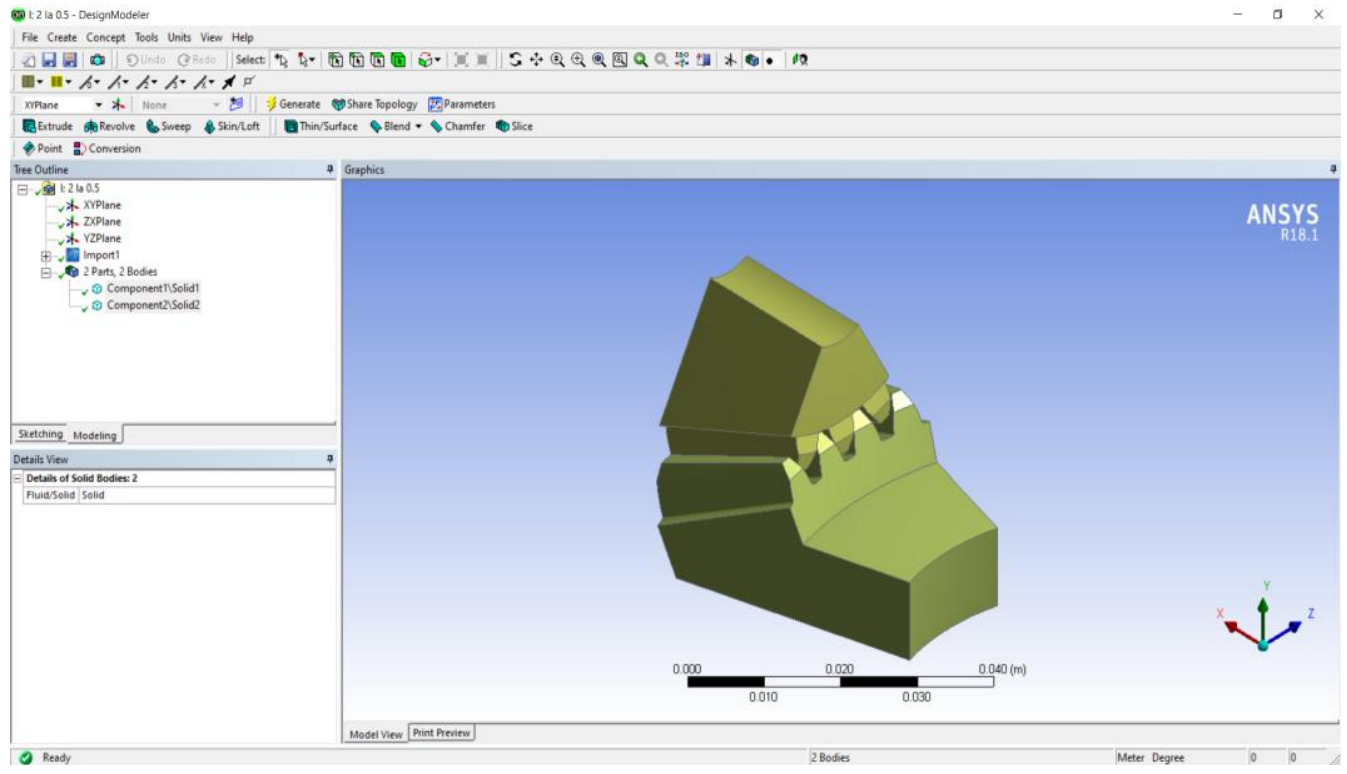

Figure 5. The model of the meshing gears for the FEM analysis

The finite element models are not built automatically. We choose to realize a discretization of the contact region and the region on the foot of the tooth with more elements and nodes, in order to obtain a result of the comportment under load with a maximum precision (figure 6) [8]

Node coordinates are determined on the gear tooth surfaces as a function of the chosen numbers of nodes in longitudinal, profile, and fillet directions.

Lateral surfaces of the bodies in contact are considered to keep the boundary conditions, represented by rigid surfaces, far enough from the contact area. The node on the axis of the pinion and the node of the gear are considered the reference in order to controls the motion.

\section{Analysis}

For simulate the comportment of the transmission under static load we take into account the material properties of the system and the load applied. The load was considered as a torque applied at the pinion body.

Concerning the materials properties, the pinion and the gear were considered made by the same material, steel, having an elastic modulus (E) of $220 \mathrm{GPa}$ and Poisson ratio $(v)$ of 0.33 . Threedimensional solid elements of type C3D8I [15] and GAP elements are used. The volume elements are used as in order to improve their bending behaviour. For the baseline design, which has an outer module of $3 \mathrm{~mm}$, a load-torque of 100 to $600 \mathrm{Nm}$ was applied to the axis of the pinion (the body of the pinion). 
The structure is composed of about 240,000 nodes and 129134 elementsand the dimension of the smaller element is around $0.5 \mathrm{~mm}$.

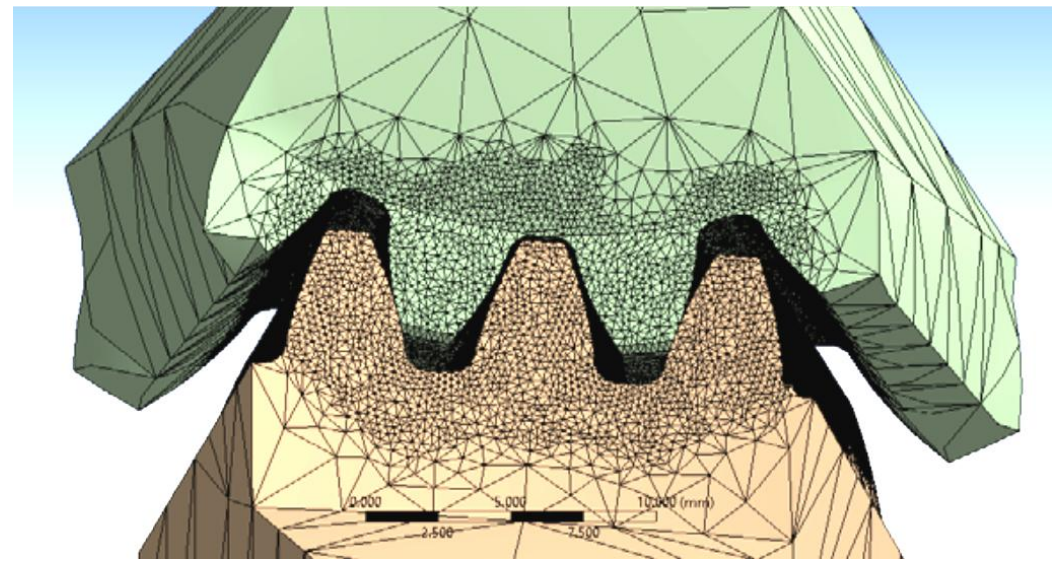

Figure 6. FEM discrete model in mesh

Concerning the contact conditions, we applied the general condition of analysis as Static structural analysis. The menu to set the contacts in the shown model is activated in ANSYS code. We can choose the type of contact between surfaces. For this simulation we chose to use contact without friction. The conditions (the surfaces) in contact are shown in the figure 7

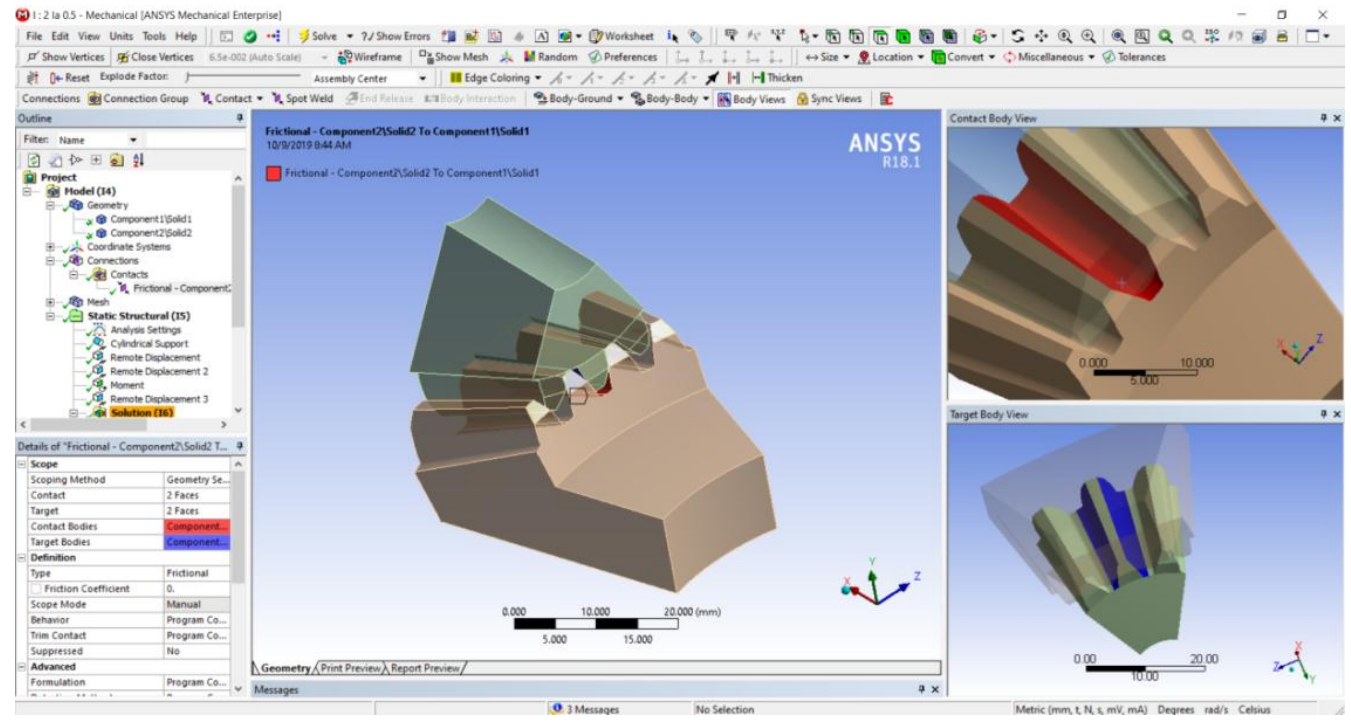

Figure 7. Surfaces sets for contact

\section{Results}

There are some aspects we were concerned to observe in this analysis. Due to elastic deformation of the system we can observe in the analysis the effect of the bending of teeth in contact at the pinion, the effect of Hertzian (local) contact between the teeth in the pair of contact and, of course, the displacements of the structure. The displacement will be considered for the segment of the wheel with the blank, as is shown in figure 5 and figure 7. The explanation of the displacement of the entire 
structure is due to the torque applied at the level of the body, from the axis of the shaft. Even if the analysis is a static analysis, we consider performing the analysis in real conditions of functioning.

For this purpose, first we study the total deformation of the structure, as it is shown in figure 8. In the figure 8 we can observe that the maximum displacement of the structure is at the tooth of the driven gear which is free to follow the displacement of the structure under load applied at the pinion. The values of the deformations (maximum) for the toques applied are shown in the figure 9.

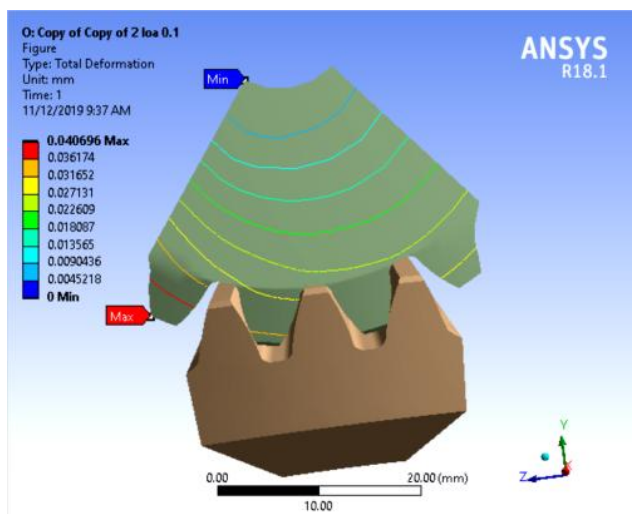

Figure 8. Displacements of the structure in mesh

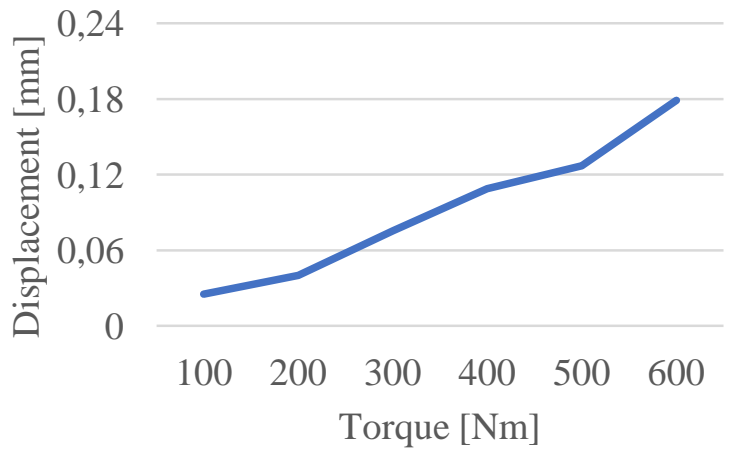

Figure 9. Displacements at the gear wheel versus load applied at pinion

Concerning the comportment of the teeth under load in the region of the foot of the tooth, we present the result of the state of stress in the region of the foot of the tooth in contact in figure 10. In figure we can see that the maximum bending stress at a load of $250 \mathrm{Nm}$ is around $260 \mathrm{MPa}$, which is in the upper part of the bending stress at elastic deformation for the gear with material and geometrical characteristics shown above.

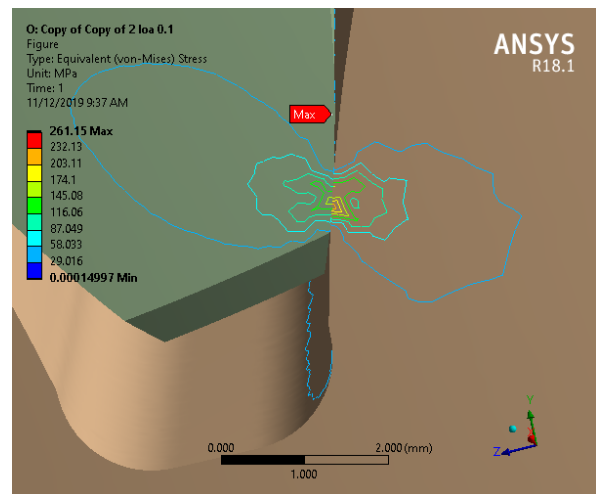

Figure 10. Bending stress analysis

Concerning the local comportment in a Hertzian contact, we present in the figure 11 the situation of contact and stress at the same level of $350 \mathrm{Nm}$ torque load. Also, the value of the stress, $1268 \mathrm{MPa}$ is similar to a real one in the same conditions of loading, for the same material and the same geometry of the structure. 


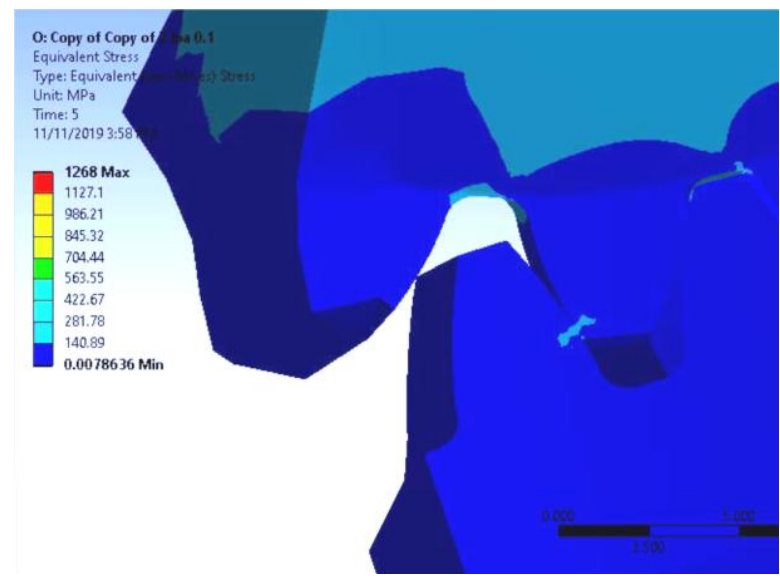

Figure 11. Hertz contact stress analysis

\section{Conclusions}

In this paper we designed on the parametric principles the geometry of the straight bevel gears. First, we designed the pinion-gear, after that the wheel -gear and finally the gears in mesh. A static analysis of the mechanical system in mesh was performed. The conditions of contact were carefully choses using the possible surfaces in meshing contact. The analysis was performed in order to find the elastic deformation of the structure, the state of bending stress at the pinion and the state of Hertzian contact stress at the pinion. The results encouraged us to consider that the design of the parts and the meshing gears is a model to follow for another useful studies.

\section{References}

[1] Litvin F L, Fuentes A, Gear Geometry and Applied Theory, 2nd Edition, Cambridge University Press, 2004.

[2] Litvin F L, Zhang Y, Wang J C, Bossler RB, Chen YJ. Design and geometry of face-gear drives. J Mech Des 1992;114(4):642-7

[3] Fuentes A. and Iserte J L, Gonzalez - Perez I., Sanchez - Marin F T, Computerized design of advanced straight and skew bevel gears produced by precision forging, Computer Methods in Applied Mechanics and Engineering 2363-2377, Elsevier. doi:10.1016/j.cma 2011.04.006

[4] Kolivand M., Ligata H., Steyer G., Benedict D.K, Chen J., Actual tooth contact analysis of straight bevel gears, J Mech Des 137(2015) 093302.

[5] Stadtfeld H J, Coniflex straight bevel gear manufacturing, Gear Solutions (2010) 40-55

[6] https://www.iso.org/obp/ui/\#iso:std:iso:23509:ed-1:v1:en

[7] https://www.iso.org/obp/ui/\#iso-ISO 1122-1:1998, Vocabulary of gear terms ; https://www.iso.org/obp/ui/\#iso:std:iso:23509:ed-1:v1:en

[8] Sorohan St, Constantinescu I N, Practica modelarii si analizei cu elemente finite, $E d$. Politehnica, Bucuresti, 2003 